\title{
Study on the Mechanized Sowing of Wheat under Water Stressed Conditions
}

\author{
Abhishek Kumar ${ }^{1 *}$, Asha Kumari ${ }^{2}$, Vishwajeet Sinha ${ }^{3}$ and Subhash Chandra ${ }^{3}$ \\ ${ }^{1}$ Indian Agricultural Research Institute, Pusa, New Delhi, India \\ ${ }^{2}$ Indira Gandhi Krishi Vishwavidyalaya, Raipur, India \\ ${ }^{3}$ Dr. Rajendra Prasad Central Agricultural University, Pusa, Bihar, India \\ *Corresponding author
}

\section{Keywords}

Flutted roller, Seed drill, Wheat crop, Germination, Seed damage, No till

Article Info

Accepted:

20 May 2019

Available Online:

10 June 2019

\section{A B S T R A C T}

Sowing is one of the important agricultural operations for raising crops. After harvest of paddy, if there is deficit moisture in the soil at the time of sowing of wheat, the germination gets affected leading to loss of yield. Handling of water treated seeds by seed drill may open a new gate of opportunities for mechanized sowing of wheat under water stressed conditions, which was the prime objective of the study. Water treated swelled seeds was found to have more weight and volume causing the variations in seed rate and also got crushed while passing through flutted rollers of the seed drill. The total seed damage expressed in percentage varied from 12 to 32 for the different levels of water treatments. Therefore, it is recommended not to use water treated seeds for sowing of wheat by flutted roller type seed metering device. It was also found that with an increase in water treatment rate, seed crushing and internal seed damage rate increased and for this friction generated over wetted seed surface could have been the prime reason. Lubricating oils along with water could be used to treat the wheat seeds in further studies. The study may also be carried out with seed drill having inclined plate type metering device to possibly obtain increase in the germination percentage.

\section{Introduction}

Improvement of the socio-economic conditions and growth of the country depends upon the development of agriculture, as majority of the population depends on it. A major percentage of the global population $(20 \%)$ resides in the Indo-Gangetic Plains (IGP), therefore it becomes a concern of utmost importance to enhance the productivity of the rice-wheat cropping systems for this region to ensure future food security (Chauhan et al., 2012). The eastern IGP has a large potential for improvement of yields, such as in the Bihar state. However, the problem of low cereal productivity of Bihar needs to be addressed on a prior basis. Over the period 2012/13-2013/14, wheat yields for this region averaged 2.34 tons/ha, as opposed to 4.79 tons/ha in the Northwestern state of Punjab (MoA, 2015). Also, the Eastern IGP has a wealth of underdeveloped water resources (Aggarwal et al., 2004; DoA, 2008). 
Bihar is a net importer of wheat with 868,000 MT purchased against a base of production of just over 5 million MT in 2010-11 (Paulsen et al., 2012). For sowing of wheat, Zero Till(ZT) may be used to conserve the natural resources and energy and also expected to increase crop yields. The typical ZT drill opens 6-13 narrow slits using inverted-T openers to place both seed and fertilizers at a depth of 7.5-10 cm (Mehla et al., 2000). In contrast, conventional-tillage (CT) practices in wheat typically involve intensive tillage with multiple passes of the tractor to accomplish ploughing, harrowing, planking, and seeding operations (Erenstein and Laxmi, 2008).

The total production of wheat can be increased either by bringing new areas under cultivation or by increasing the production in existing cultivable land. However, much of the success is dependent upon the availability and quality of inputs and their management. Increase in production per unit area is not possible through primitive means. Hence, now increased production per unit area is greatly possible by the use of newly improved agricultural techniques.

Application of fertilizer at the proper location also has a good effect on crop growth and yield. For proper sowing of agricultural crops, correct seed rate, proper placement of seeds and fertilizers, row spacing, correct application of fertilizer with respect to seed and proper compaction considerations are very important factors. Seed bed preparation consumes a lot of energy and time which results in delay of wheat sowing and consequently reduction in yield. A No-till drill machine can be used directly to sow wheat in one pass without tillage. The No-till drill can even be used for sowing seeds in well tilth soil that is being already practiced by majority of the farmers in Bihar. Generally, the seed metering mechanism is of the fluted roller type, which is taken in the present study.
The water treated seeds have their endosperm saturated and thereby facilitates germination. The sowing of water treated seeds for wheat cultivation by seed drill is not being practiced by the farmers under moisture deficit conditions as yet, besides the fact that such seeds give early germination and better crop establishment as compared to untreated dry seeds. The chances of delicate seeds being damaged due to impact action of flutted roller may not be completely ruled out. Since, to the best of researcher's knowledge, such kinds of studies have not been ever conducted, this study was planned with the following objectives:

The aim was to determine seed crushing, internal seed damage and germination of water treated seeds for seed drill with flutted roller type metering device. Also, moisture absorbance of treated seeds under different treatments at similar conditioning time was to be seen. Appropriate rate of water treatment and corresponding appropriate seed rate for optimum plant population was also determined in the study.

\section{Materials and Methods}

This chapter deals with methodological approach of present study conducted in laboratory as well as in actual field conditions involving calibration of seed rate, physical properties of soil, germination and seed crushing besides field performance of machine under use for the different treatments.

\section{Description of experimental site}

\section{Experimental site}

The experiment was conducted both in the laboratory of Farm Machinery Department of C.A.E, R.A.U, PUSA as well as in the field of R.A.U, Pusa Farm. The experimental plot was 
located at an altitude of $52.99 \mathrm{~m}$ above the mean sea level with $25^{\circ} 59^{\prime} \mathrm{N}$ latitude and 85 48 ' E longitude. The climate of the area is subtropical with an average annual rainfall of $1192 \mathrm{~mm}$.

\section{Soil properties}

As per available data provided by the Department of Soil Science, R.A.U., PUSA, the following indicates the physical properties of soil for the experimental plot. The soil texture was Silty type and the bulk density was found to be $1.239 \mathrm{gcm}^{-3}$.

\section{Composition of the soil}

Sand $-43 \%$

Silt $-46 \%$

Clay- $11 \%$

\section{Seed details}

Seed variety: Hi 1563

Seed moisture: $11.9 \%$

1000 grain weight: $40 \mathrm{gm}$

\section{Machine specifications}

Name: Zero till seed-cum fertilizer drill

Metering system for seed: Flutted roller

Make: 2012

Model number: 0240

No. of tynes: 11

Tyne-tyne distance: $18.9 \mathrm{~cm}$

Drive wheel diameter: $40 \mathrm{~cm}$

\section{Calibration of seed drill}

Calibration of seeding implements is necessary before putting it in actual use. The zero till seed cum fertilizer drill used in the present investigation was calibrated for 100 $\mathrm{kg} / \mathrm{ha}$ seed rate as shown in Fig. 1. The standard procedure for calibration was adopted:

For calibration of seed drill, seed weight for area corresponding to 25 revolutions of drive wheel was computed at the desired seed rate on hectare basis. Now with the help of seed metering device actuating lever, the machine was set to deliver seed for a fixed opening of seed port. The drive wheel was then rotated for 25 revolutions and seed discharged through all of seed tubes were collected and weighed. If the discharged seed for 25 revolutions of drive wheel is as the desired seed rate, the calibration of seed drill is acceptable. If this is not so, by hit and trial method, seed port opening is increased or decreased by the lever and the process is repeated, till the seed drill is calibrated for discharge of seed at the desired seed rate.

The desired seed rate for 25 revolutions of drive wheel was worked out by the following procedure:

Number of furrow openers $=\mathrm{N}$

Distance between two furrow openers $=\mathrm{W}$, meter

Desired seed rate $=\mathrm{R} \mathrm{kg} / \mathrm{ha}$

Diameter of drive wheel $=\mathrm{D}$, meter

Working width of sowing machine $=\mathrm{N} \times \mathrm{W}$, meter

Distance covered in 25 revolution of drive wheel $=\pi \times \mathrm{D} \times 25$

Area covered in 25 revolution = $\mathrm{N} \times \mathrm{W} \times \pi \times \mathrm{D} \times 25 \mathrm{~m}^{2}$

If desired seed dropping for $\mathrm{N} \times \pi \times \mathrm{D} \times 25 \times \mathrm{W}$ $\mathrm{m}^{2}$ is $\mathrm{Y} \mathrm{kg}$

Then $\mathrm{Y}=\frac{R}{10000} \times \mathrm{N} \times \pi \times \mathrm{D} \times 25 \times \mathrm{W}$

Desired seed dropping from each tyne $=\frac{Y}{11} \mathrm{~kg}$

The 11-tyne Zero Till seed-cum fertilizer drill 
was calibrated for $100 \mathrm{~kg}$ seed rate by hit and trial methods by adopting the above discussed procedure till total discharge of seed from all the tynes reached to a value of $\mathrm{Y}$ calculated by taking the value of Seed Rate $(\mathrm{R})=100$ $\mathrm{kg}$, width of the machine $(\mathrm{N} \times \mathrm{W})=2.079 \mathrm{~m}$ and Diameter of the drive wheel (D) $=0.4 \mathrm{~m}$ for the machine under use in the present study.

\section{Computation of seed crushing}

After calibration of seed drill for recommended seed rate, the drive wheel was provided twenty-five revolutions and weight of seed dropped was noted. The dropped seeds were counted and sorted into healthy and damaged seeds.

The sorted damaged seeds were then counted. Total five readings were taken for each treatment. Average of these readings resulted into the percentage damage of seed by the metering device. The following formula was used for computation of percentage seed damage.

Percentage seed damage $=\frac{N_{D}}{N} \times 100$

Where,

$\mathrm{N}_{D}=$ average number of damaged seeds

$\mathrm{N}=$ total number of dropped seeds

\section{Determination of soil moisture}

For calculation of moisture content, a core sampler, moisture boxes, oven, desiccators with calcium chloride as active desiccant and electronic balance were used. Soil samples were taken with the help of core sampler as per established procedure and were placed in the moisture boxes. Weight of these samples was taken with the help of a weighing balance. These boxes with lids off, were placed in the oven at a temperature of $105^{\circ} \mathrm{C}$ for 24 hours to dry the soil sample.

The percentage moisture content was determined by using the following formula:

Percentage soil moisture content $=$

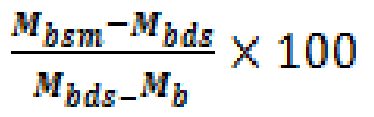

Where,

$\mathrm{M}_{\mathrm{b}}=$ Mass of empty moisture box, $\mathrm{g}$

$\mathrm{M}_{\mathrm{bsm}}=$ Mass of moisture box + moist soil, $\mathrm{g}$

$\mathrm{M}_{\mathrm{bds}}=$ Mass of moisture box + dry soil, $\mathrm{g}$

$\mathrm{M}_{\mathrm{bsm}}-\mathrm{M}_{\mathrm{bds}}=$ Mass of moisture in the soil, $\mathrm{g}$

$\mathrm{M}_{\mathrm{bds}}-\mathrm{M}_{\mathrm{b}}=$ Mass of dry soil, $\mathrm{g}$

\section{Determination of seed moisture}

A most widely used oven drying method was adopted for measurement of moisture content of the grains. A clean moisture box was taken and weighted with lid. The sample of required quality of grain was kept in the moisture box and weight of the box with lid was taken to balance to an accuracy of $0.1 \mathrm{~g}$. Then the sample was oven dried at the temperature of $105^{\circ} \mathrm{C}$ for 24 hours. Final weight of moisture box with dry grain was taken on the same balance. Five samples were taken from the field. Moisture content of sample grain was calculated by using following formula (Sahay and Singh, 1998).

Percentage grain moisture content $=$

$\frac{W_{2}-W_{3}}{W_{3}-W_{1}} \times 100$

Where,

$\mathrm{W}_{1}=$ Weight of box only (in grams)

$\mathrm{W}_{2}=$ Weight of box with wet grain (in grams)

$\mathrm{W}_{3}=$ Weight of box with dry grain (in grams) 


\section{Determination of discharge of sprayer}

For the determination of discharge of the sprayer, first of all sprayer was full charged then it was flushed with clean water for removal of dust particles.

Then water was discharged in a container through the sprayer for every one-minute interval and volume of water was measured by a measuring flask for one minute. The process was repeated 10 times and average discharge was measured as shown in table 1:

\section{Determination of quantity of water to be applied and sprayer operation time}

For the treatments under the present investigation, water is to be applied to the seeds@ @2\%,4\%,6\%,8\% and 10\% by weight of seed. This was worked out by using the following formula:

$\mathrm{W}_{\mathrm{a}}=\mathrm{W}_{\mathrm{s}}{ }^{\mathrm{X}} \mathrm{p}$

Where,

$\mathrm{W}_{\mathrm{a}}=$ water to be applied

$\mathrm{W}_{\mathrm{s}}=$ weight of seed in $\mathrm{kg}$

$\mathrm{p}=$ percentage of water to be applied under different treatments

Sprayer operation time is worked with using the given formula:

$\mathrm{t}=\frac{W_{a}}{D}$

Where $\mathrm{t}=$ sprayer operating time, minute

$\mathrm{W}_{\mathrm{a}}=$ quantity of water to be applied, $\mathrm{ml}$

$\mathrm{D}=$ discharge of spraying in $\mathrm{ml} / \mathrm{min}$

Determination of spraying time for knapsack battery operated sprayer

The treatments include application of water in uniform pattern and at a determined rate. This cannot be possible manually. The sprayer is an efficient equipment that may apply determined quantity of water, it is necessary that discharge rate of available sprayer be determined or known. Once the discharge rate will be known, the time for applying a fixed quantity of water can easily be worked out by using formula and the calculations are shown in table 2 .

$\mathrm{t}=\frac{W_{a}}{Q}$

Where $\mathrm{t}=$ time of operation of sprayer in second

$\mathrm{W}_{\mathrm{a}}=$ Quantity of water to be applied by sprayer in $\mathrm{ml}$

$\mathrm{Q}=$ Discharge rate of sprayer in $\mathrm{ml} /$ second

\section{Germination test for treated and untreated seeds}

After handling through seed drill, the treatment treated seeds were put in the separate tray for germination test. Each tray was filled with soil up to 2 inches. 100 healthy seeds were collected from each treatment and broadcasted into separate trays respectively.

After the broadcasting, seeds were covered by soil up to 1 inch. Treated seeds were investigated for germination on daily basis with application of $160 \mathrm{ml}$ of water at 3 days interval to maintain the soil moisture. This process was continued up to 20 days and germination data from each tray was recorded. The data collected on the 20th day were taken for germination count as shown in Fig. 2.

\section{Determination of internal damage of seeds}

After completion of 20 days observation, the 
germination percentage from each tray was recorded. The germination percentage of treated seeds was subtracted from germination percentage of untreated seeds. The difference in germination percentage of untreated and treated seeds provided the information with regards to internal damage caused to the seeds due to the impact of flutted roller.

\section{Results and Discussion}

Under this chapter, the results of the experiment carried out with various treatments have been complied, presented in tabular form and discussed in details by explaining the proper causes, factors and with due considerations to objectives, aiming to which the experiment was planned and executed. This chapter deals with the various seed parameters like seed crushing, internal injury, moisture absorbance and the required seed top-up amount to achieve the calibrated value of seed rate, at a fixed opening of the seed port.

\section{Effect of moisture absorbance of treated seeds at similar conditioning time}

Data indicating moisture absorbance percentage for differently treated seeds for 90-minute conditioning time has been presented in the Fig. 3 below, where mc on the $\mathrm{y}$ axis represents moisture content in percentage and $x$ axis represents the different treatments.

From perusal of data of moisture absorbance of seeds for different treatments presented in figure 3 , it is clear that the moisture absorbance for treated seeds was found to be maximum for treatment $\mathrm{T}_{5}$ by $27.11 \%$ followed by treatment $\mathrm{T}_{4}(24.79 \%)$ and treatment $\mathrm{T}_{3}(19.61 \%)$ and the moisture absorbance of treated seed was minimum for treatment $\mathrm{T}_{1}(15.2 \%)$. From the graph it is evident that water application amount on seeds has a direct co-relation with its moisture absorbance under unsaturated condition. For all treatments, the moisture content of treated seeds increased with increase in amount of water applied to a fixed mass of seed for fixed seed conditioning time.

\section{Seed crushing and germination parameters}

Seed crushing, internal seed damage and germination rate of treated and untreated seeds under trail has been presented in table 3 below:

From perusal of data in table 3 , it is evident that for treatment $T_{5}$ total seed damage percentage was found to be maximum (32\%), followed by treatment $\mathrm{T}_{4}$ and treatment $\mathrm{T}_{3}$. The seed damage was minimum in case of treatment $T_{1}$. The data presented with respect to seed crushing and internal seed damage in table 3 above shows increasing trend as the water content in the seed is increased. The increasing value of seed crushing and internal seed damage might be because of two reasons. Increase in water content would have made the endospermsoft due to the moisture. The soft-endosperm after being heated by the flutted roller might have caused the injury to the embryo of seeds and that ultimately would have resulted into lower seed germination percentage of seeds in increasing order for different treatments having increasing rate of water application.

Seed top-up amount corresponding to varying rates of water application on seeds for different treatments

The seed top-up amount needed to compensate the deficit in actual healthy seed delivery for meeting the calibrated value of seed rate has been presented below in table 4 . 
Fig.1 A view of calibration of seed drill

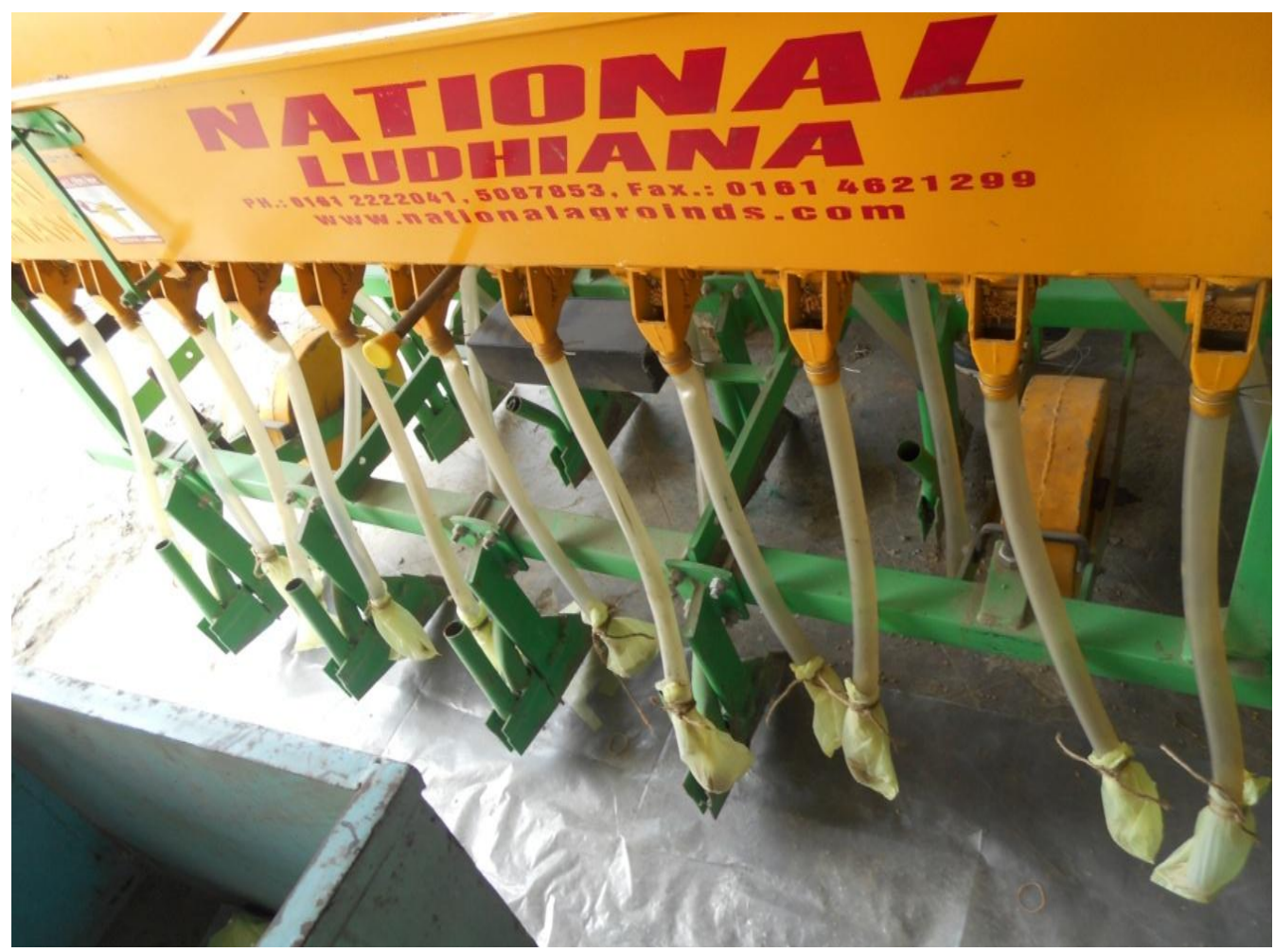

Fig.2 A view of the germination tray

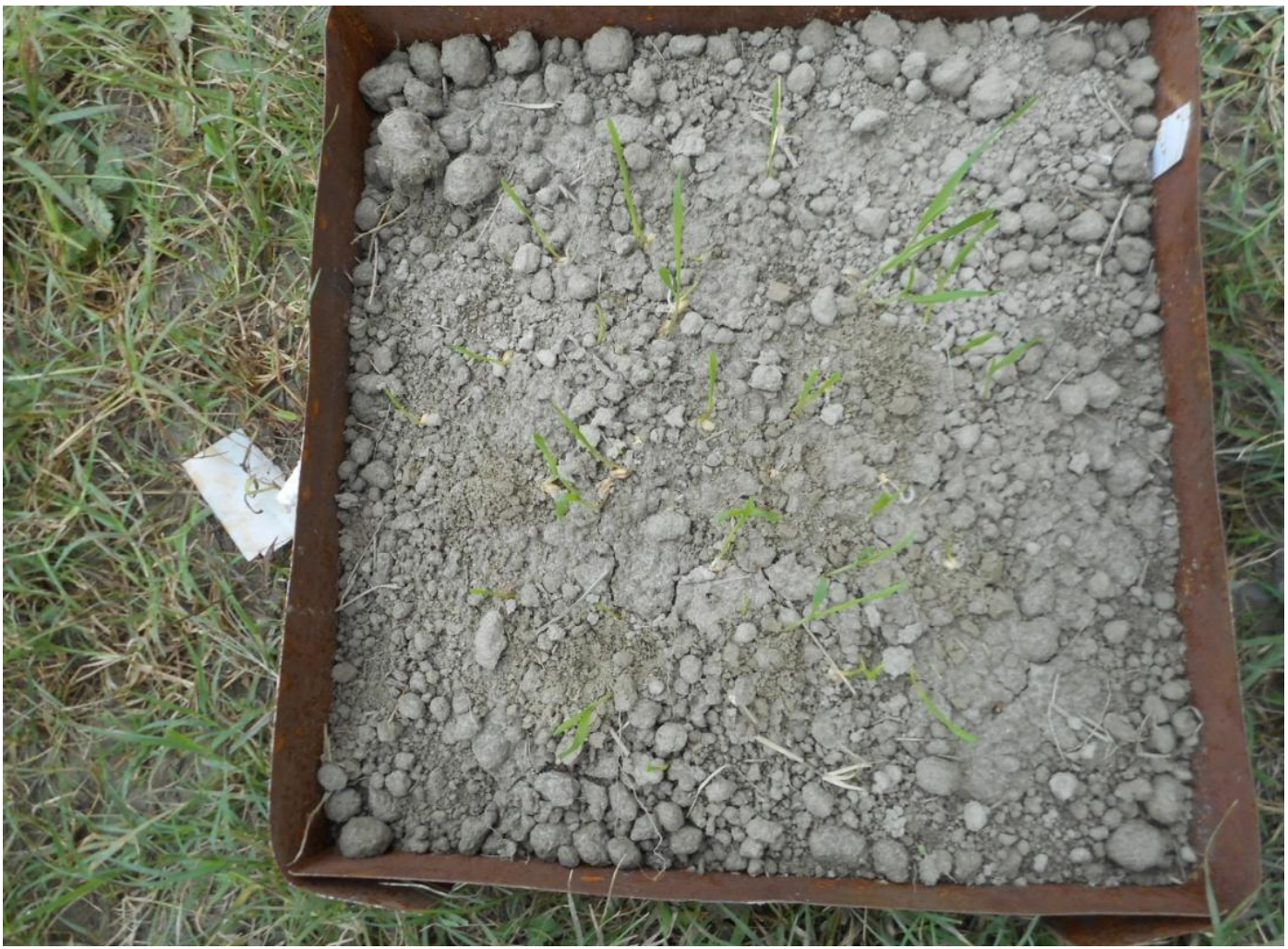


Fig.3 Moisture absorbance of treated seeds for different treatments at 90 minute conditioning time

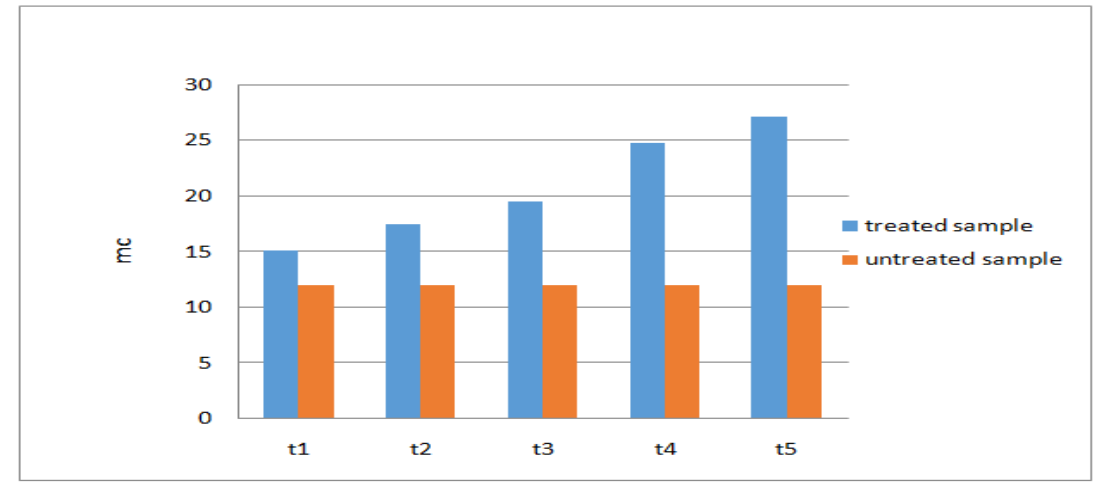

Table.1 Calculation of discharge of sprayer

\begin{tabular}{|c|c|c|}
\hline Activity No. & Time(second) & Volume(ml) \\
\hline $\mathbf{1}$ & 60 & 955 \\
\hline $\mathbf{2}$ & 60 & 975 \\
\hline $\mathbf{3}$ & 60 & 990 \\
\hline $\mathbf{4}$ & 60 & 1020 \\
\hline $\mathbf{5}$ & 60 & 1005 \\
\hline $\mathbf{6}$ & 60 & 1010 \\
\hline $\mathbf{8}$ & 60 & 995 \\
\hline $\mathbf{9}$ & 60 & 990 \\
\hline $\mathbf{1 0}$ & 60 & 1005 \\
\hline Average & 60 & 1000 \\
\hline
\end{tabular}

Table.2 Calculation of the sprayer operation time

\begin{tabular}{|c|c|c|c|c|c|}
\hline Treatments & $\begin{array}{c}\text { Sample seed } \\
\text { wt } \mathbf{( k g})\end{array}$ & $\begin{array}{c}\text { \% of water to } \\
\text { be applied by } \\
\mathbf{w t}\end{array}$ & $\begin{array}{c}\text { Quantity of water } \\
\text { in ml to be applied } \\
(\mathbf{m l})\end{array}$ & $\begin{array}{c}\text { Discharge rate of } \\
\text { sprayer (ml/min) }\end{array}$ & $\begin{array}{c}\text { Time of } \\
\text { spraying in } \\
\text { seconds }\end{array}$ \\
\hline $\mathbf{T}_{\mathbf{1}}$ & 8 & 2 & 160 & 994.5 & $9.65 \approx 10$ \\
\hline $\mathbf{T}_{\mathbf{2}}$ & 8 & 4 & 320 & 994.5 & $19.3 \approx 20$ \\
\hline $\mathbf{T}_{\mathbf{3}}$ & 8 & 6 & 480 & 994.5 & $28.95 \approx 30$ \\
\hline $\mathbf{T}_{\mathbf{4}}$ & 8 & 8 & 640 & 994.5 & $38.6 \approx 40$ \\
\hline $\mathbf{T}_{\mathbf{5}}$ & 8 & 10 & 800 & 994.5 & $48.25 \approx 50$ \\
\hline
\end{tabular}

Table.3 Seed damage and germination rate of treated seeds

\begin{tabular}{|c|c|c|c|c|}
\hline Treatments & Seed crushing (\%) & Internal injury (\%) & Total damage (\%) & Germination (\%) \\
\hline $\mathrm{T}_{1}$ & 9 & 3 & 12 & 93 \\
\hline $\mathrm{T}_{2}$ & 12 & 9 & 21 & 87 \\
\hline $\mathrm{T}_{3}$ & 13 & 10 & 23 & 86 \\
\hline $\mathrm{T}_{4}$ & 15 & 12 & 27 & 84 \\
\hline $\mathrm{T}_{5}$ & 18 & 14 & 32 & 82 \\
\hline
\end{tabular}

Note: Germination of untreated seeds $=96 \%$ 
Table.4 Required seed top-up amount in different treatments for achieving the calibrated seed rate

\begin{tabular}{|c|c|c|c|c|c|c|}
\hline \multirow[t]{2}{*}{ Treatments } & \multicolumn{2}{|c|}{ Seed rate $(\mathrm{kg} / \mathrm{ha})$} & \multirow[b]{2}{*}{$\begin{array}{c}\text { Difference of } \\
\text { calculated value } \\
\text { of seed rate } \\
\text { from calibrated } \\
\text { value }\end{array}$} & \multirow[b]{2}{*}{$\begin{array}{l}\text { Total seed } \\
\text { damage } \\
\text { (crushing } \\
\text { +internal } \\
\text { injury) } \\
\text { (kg/ha) }\end{array}$} & \multirow[b]{2}{*}{$\begin{array}{l}\text { Total seeding } \\
\text { gap } \\
\text { calculated on } \\
\text { calibrated } \\
\text { value of seed } \\
\text { rate }(\mathrm{kg} / \mathrm{ha})\end{array}$} & \multirow[b]{2}{*}{$\begin{array}{c}\text { Quantity of } \\
\text { seed desired } \\
\text { as top-up } \\
\text { value for } \\
\text { achieving } \\
\text { the } \\
\text { calibrated } \\
\text { value of seed } \\
\text { rate(kg/ha) }\end{array}$} \\
\hline & $\begin{array}{l}\text { Treated seed rate } \\
\text { at different } \\
\text { moisture content }\end{array}$ & $\begin{array}{l}\text { Weight equivalence } \\
\text { of untreated seed at } \\
11.9 \% \text { moisture } \\
\text { content } \\
\text { corresponding to } \\
\text { treated seeds under } \\
\text { different treatments }\end{array}$ & & & & \\
\hline $\mathrm{T}_{1}$ & $81.44 *(15.2)$ & 79.10 & 19.7 & 11.85 & 31.55 & 31.55 \\
\hline $\mathrm{T}_{2}$ & $82.27 *(17.5)$ & 78.31 & 20.49 & 21.73 & 42.22 & 42.22 \\
\hline $\mathrm{T}_{3}$ & $84.3 *(19.61)$ & 78.93 & 19.87 & 20.74 & 40.61 & 40.61 \\
\hline $\mathrm{T}_{4}$ & $85.41 *(24.79)$ & 76.58 & 22.22 & 26.67 & 48.89 & 48.89 \\
\hline $\mathrm{T}_{5}$ & $87.41 *(27.11)$ & 76.94 & 22.26 & 31.6 & 53.86 & 53.86 \\
\hline
\end{tabular}

Calibrated seed rate $=98.80 \mathrm{~kg} / \mathrm{ha}$

Moisture content of untreated seeds $=11.9 \%$

*Data in the parenthesis indicates the moisture content of the treated seeds in percentage. 
The seed rate obtained from the seed drill under different treatments and their weight equivalence at $11.9 \%$ moisture content (moisture content of untreated seed) shows antagonistic relationship with increase in different treatments. The seed rate of treated seeds increases from treatment $T_{1}$ to $\mathrm{T} 5$. However, the equivalent seed rate at moisture content of untreated seeds starts decreasing from treatment $T_{1}$ to $T_{5}$. This type of reverse relation between delivery of treated seeds and weight equivalence of untreated seeds must have been only because of increasing rate of moisture absorbance of seeds from treatment $\mathrm{T}_{1}$ to $\mathrm{T}_{5}$.

The sum total deficit in seed rate of treated computed as weight equivalence of untreated seeds upon addition with total seed damage quantity, represented as total seeding gap has been presented in table 4, clearly shows the increasing trend in seeding gap of treated seeds over the calibrated value of seed rate for untreated seeds. This type of trend is because of the decreasing value of seed rate of untreated seeds worked out as weight equivalence of treated seeds at $11.9 \%$ moisture as well as increasing value of total seed damage quantity in different treatments i.e. $\mathrm{T}_{1}$ to $\mathrm{T}_{5}$.

The seed top-up quantity is nothing but quantity of seed need to be added with recommended seed rate at which the seed drill may be in position to deliver the healthy seeds at rate equal to the weight of untreated seeds at desired seed rate and from table 4, the values of seed gap in all above treatments is calculated and recommended for field use.

Summary and conclusion is as follows:

The seed crushing and internal injury i.e. total damage was found to be maximum for the treatment $\mathrm{T}_{5}(32 \%)$ and minimum for the treatment $\mathrm{T}_{1}(12 \%)$. Therefore, use of water treated wheat seeds with fluted roller type mechanism are not recommended due to the total damage present being one of the prime reasons. The seed germination percentage was maximum for treatment $\mathrm{T}_{1}(93 \%)$ and minimum for treatment $\mathrm{T}_{5}(82 \%)$. Inclined plate type seed metering mechanism could be used for the water treated wheat seeds along with some lubricating oil, to possibly improve germination. The moisture absorption for the treated samples was found to be maximum (27.11\%) for treatment $\mathrm{T}_{5}$ and minimum (15.2\%) for treatment $T_{1}$. The desired seed quantity as top-up value for achieving the calibrated value of seed rate $(53.21 \mathrm{~kg} / \mathrm{ha})$ was found to be maximum for treatment $\mathrm{T}_{5}$ whereas minimum $(31.17 \mathrm{~kg} / \mathrm{ha})$ for the treatment $\mathrm{T}_{1}$. Therefore, as water content of the wheat seeds was increased, the additional requirement of the seeds also increased to bring the seed rate at par with the calibrated seed rate value.

\section{References}

Aggarwal, P. K., Joshi, P. K., Ingram, J. S., and Gupta, R. K. (2004). Adapting food systems of the Indo-Gangetic plains to global environmental change: key information needs to improve policy formulation. Environmental Science \& Policy, 7(6), 487-498.

Chauhan, B. S., Mahajan, G., Sardana, V., Timsina, J., and Jat, M. L. (2012). Productivity and sustainability of the rice-wheat cropping system in the IndoGangetic Plains of the Indian subcontinent: problems, opportunities, and strategies. In Advances in Agronomy (Vol. 117, pp. 315-369). Academic Press.

DoA. (2008). Bihar's Agricultural Development: Opportunities and Challenges - A report of the special task force on Bihar Department of Agriculture. New Delhi: Government of 
India.

Erenstein, O., and Laxmi, V. (2008). Zero tillage impacts in India's rice-wheat systems: a review. Soil and Tillage Research, 100(1-2), 1-14.

Mehlka, R. S., Verma, J. K., Gupta, R. K., and Hobbs, P. R. (2000). Stagnation in the productivity of wheat in the indogangetic plains: zero-till-seed-cumfertilizer drill as an integrated solution (No. CIMMYT.).

MoA. (2015). Agricultural Statistics at a
Glance 2014. New Delhi: Department of Agriculture and Cooperation, Ministry of Agriculture, Government of India.

Paulsen, J., Bergh, K., Chew, A., Gugerty, M. K., and Anderson, C. L. (2019). Wheat value chain: Bihar. F1000Research, 3.

Sahay, K.M. and Singh, K.K. (1994). Unit operations of agricultural processing. Vikas Publishing House Pvt. Ltd., New Delhi, pp. 7-8

\section{How to cite this article:}

Abhishek Kumar, Asha Kumari, Vishwajeet Sinha and Subhash Chandra. 2019. Study on the Mechanized Sowing of Wheat under Water Stressed Conditions. Int.J.Curr.Microbiol.App.Sci. 8(06): 2770-2780. doi: https://doi.org/10.20546/ijcmas.2019.806.334 